\title{
Aquisição e complexidade em narrativas multimídia de aprendizagem ${ }^{1}$
}

Vera Lúcia Menezes de Oliveira e Paiva

UFMG/CNPq/FAPEMIG

We tell our lives as narratives, but we experience them as hypertexts.

Jay Lemke

\begin{abstract}
RESUMO: Este artigo apresenta reflexões sobre a aquisição de língua inglesa, entendida como sistema complexo em uma perspectiva êmica. Para tanto, discute aspectos da pesquisa narrativa, da multimodalidade e da complexidade da aquisiçãao de segunda língua. Como evidências empíricas da aquisição, esta pesquisa utiliza excertos de narrativas multimídia de aprendizagem de língua inglesa, em que os narradores revelam aspectos de seus processos de aprendizagem por meio de textos, hipertextos, imagens e sons. Essas narrativas mostram que o processo de aquisiçãao é um sistema complexo e que a segunda língua emerge da interação entre as diferentes experiências de aprendizagem dentro e fora do ambiente escolar.

PALAVRAS-CHAVE: aquisição, pesquisa narrativa, multimídia, complexidade.
\end{abstract}

\section{Introdução}

Aprender inglês no Brasil não é uma tarefa fácil devido às limitações contextuais, à ausência de input autêntico no ambiente escolar e às poucas oportunidades de uso do idioma em situações reais. Apesar desse contexto adverso, é surpreendente como alguns aprendizes atingem um bom comando da língua inglesa como veremos em algumas narrativas que ilustram este artigo.

A pesquisa sobre aquisição de uma língua estrangeira é uma tarefa desafiadora, pois não temos como penetrar na mente dos aprendizes e nem como observar todas as suas experiências. No entanto, as narrativas de aprendizagem de línguas estrangeiras (NALEs) podem revelar diferentes aspectos da complexidade da aquisição de uma segunda língua (ASL). As

${ }^{1}$ Este artigo é uma versão em português do texto "Multimedia language learning histories", capítulo do livro Narratives of Learning and Teaching EFL, editado por Paula Kalaja, Vera Menezes e Ana Maria F Barcelos, e publicado pela Palgrave-Macmillan em 2008. 
reflexões pessoais nesses textos reúnem eventos escolares, experiências particulares, questóes de identidade, crenças, medos, preferências, e relações pessoais e institucionais. A compreensão dos próprios aprendizes sobre como as línguas são aprendidas, além de representar suas experiências individuais, podem também fornecer insights importantes sobre ASL.

Neste estudo, procurei recorrências em narrativas multimídia dos aprendizes de inglês que pudessem me ajudar a responder as seguintes perguntas: (1) O que os aprendizes nos dizem sobre ASL entendida como um sistema complexo? e (2) Que tipo de conhecimento emerge da interação entre texto, hipertexto, imagens e sons em narrativas multimídia de aprendizagem?

Na seção 2, eu discuto aspectos da pesquisa narrativa, da multimodalidade, da complexidade e da ASL. O corpus das narrativas é descrito na seção 3, e, na 4, analiso alguns exemplos selecionados das narrativas multimídia. $\mathrm{Na}$ conclusão, eu argumento que a ASL emerge da interação entre as diferentes experiências com a segunda língua.

\section{O contexto deste estudo}

Tenho trabalhado com pesquisa narrativa (PAIVA, 2006a, 2006b) em diálogo com a teoria do caos para tentar entender como os aprendizes adquirem a língua inglesa em contextos onde ela não é falada. Meu interesse recente reside em narrativas multimídia (PAIVA, 2006c), pois uma gama maior de informações emerge da combinação de textos, hipertextos, imagens e sons.

Como já apontado por Larsen-Freeman (2000, p.169), os aprendizes de línguas têm sido investigados pela perspectiva ética (etic). Ao trabalhar com NALEs e ouvir a voz dos próprios aprendizes, nosso objetivo é mudar o foco da pesquisa em busca de uma perspectiva êmica. A perspectiva 'ética' se refere à interpretação externa do pesquisador e 'êmica' à interpretação dos aprendizes de suas próprias experiências de aprendizagem. O foco nas experiências dos próprios aprendizes ajuda o pesquisador a mudar o foco do objetivismo/ subjetivismo para o experiencialismo em busca de uma melhor compreensão de como as línguas são aprendidas, observando o ponto de vista do próprio aprendiz. Na perspectiva experiencialista, o homem é visto como parte do ambiente, em constante interação com o mesmo. O homem transforma o ambiente e é transformado por ele.

Lakoff e Johnson (1980) vêem o objetivismo, o subjetivismo e o experiencialismo como mitos e explicam que não estão usando o termo mito no sentido pejorativo. Eles consideram que "assim como as metáforas, os 
mitos são necessários para atribuir sentido do que se passa no nosso entorno. Todas as culturas têm mitos e as pessoas não podem funcionar sem eles, assim como não podem funcionar sem a metáfora" ${ }^{2}$ (LAKOFF; JOHNSON, 1980, p.185-186). Os autores optam pelo mito do experiencialismo, pois este não coloca em oposição aspectos externos e internos da compreensão como fazem o objetivismo e o subjetivismo. Na perspectiva experiencialista, o homem é visto como parte do ambiente, em constante interação com o mesmo. O homem altera o ambiente e é por ele modificado.

O estudo das NALEs reforça a perspectiva experiencialista porque os narradores falam sobre suas constantes interações em ambientes diferentes e sobre as mudanças que vão experimentando.

\subsection{Pesquisa Narrativa}

As NALEs dão voz aos aprendizes que, freqüentemente, falam sobre suas experiências em contextos diferentes da sala de aula tradicional. Os narradores falam livremente sobre suas memórias e suas emoções ao dar sua própria explicação sobre como aprendem ou aprenderam uma outra língua. Esses relatos nos ajudam a entender certos aspectos envolvidos na aquisição de uma língua (ex. medo, ansiedade, influência familiar, etc.) que não são facilmente identificados por meio de outros instrumentos de pesquisa.

Com o objetivo de compreender as experiências de aprendizagem, vários pesquisadores têm feito uso de NALEs. Pavlenko (2001, p. 213), por exemplo, acredita que esse tipo de narrativa é uma fonte única de informação sobre a motivação dos aprendizes, suas experiências, lutas, perdas e ganhos; McGroarty (1998, p. 598) considera que "autobiografias e memórias de aprendizes altamente letrados e reflexivos têm acrescentado observações impressionantes sobre os aspectos subjetivos da experiência de se aprender uma língua”.

$\mathrm{O}$ crescente interesse sobre os relatos em primeira pessoa deu origem a publicações como as de Benson e Nunan (2002, 2004). Pesquisadores têm analisado tanto experiências de aprendizagem de línguas em biografias publicadas em livros como Pavlenko (2001) ou coletando NALES entre alunos (ver MURPHEY; CHEN; CHEN 2005). Alguns pesquisadores usam suas próprias histórias, com, por exemplo, So e Dominguez (2005), ou narrativas coletadas em diários de aprendizagem, como Swain e Miccoli (1994) e entrevistas, como Shoaib e Dörnyei (2005).

${ }^{2}$ Essa e todas as demais traduções são de minha responsabilidade. 
No meu próprio trabalho, venho utilizando narrativas multimídia, pois entendo que as imagens e sons não apenas ilustram os textos escritos, mas compõem uma rede ampla de significados. Para entender a produção de sentido das imagens, uso como suporte a gramática visual desenvolvida por Kress e van Leeuwen (1996). Esses autores entendem que as estruturas pictóricas "têm uma dimensão semântica de profunda importância" (p. 45). Acredito que o mesmo pode ser dito a respeito dos sons.

Gerard e Goldstein (2005, p.6) dizem que "quando se adiciona áudio a imagens e texto, isso equivale a um milhão de palavras". Em uma clara referência aos sistemas complexos - emergência - eles ressaltam que "palavras e imagens representam muito mais do que a soma de suas partes". De fato, pode-se dizer que a multimodalidade carrega muito mais informação do que faz cada modalidade individualmente, pois o significado emerge das interações entre as diferentes modalidades empregadas pelo produtor do texto.

$\mathrm{Na}$ seção 2.3, apresento algumas características dos sistemas complexos, da teoria do caos e da ASL, com o objetivo de compreender a aquisição por meio da narração de experiências registradas nas NALES multimídia.

\subsection{Caos/complexidade}

A teoria do caos e os estudos sobre complexidade têm influenciado diferentes campos de investigação, incluindo a educação. Gistrap (2005, p. 57) ressalta que a compreensão das metáforas do caos poderia nos ajudar a entender os ambientes educacionais complexos e os paradoxos dos sistemas adaptativos complexos, que, de acordo com Velve et al. (2002, p. 2), são entidades abertas compostas por elementos que se relacionam. ASL pode ser entendida como um exemplo de sistema complexo. É um sistema aberto a novas informaçōes em um fluxo contínuo que o move a estágios mais complexos. A próxima seção apresenta uma visão geral sobre ASL como um sistema complexo.

\subsubsection{A ASL como um sistema complexo}

Larsen-Freeman (1997, p.141) foi a primeira a observar que "há similaridades salientes entre a nova ciência do caos/complexidade e a aquisição de segunda língua". Ela entende que a ASL compartilha as mesmas características de outros sistemas complexos.

Para que um sistema complexo evolua, existem atratores periódicos responsáveis por comportamentos repetitivos e periódicos. Atratores são definidos por Lewin (1992, p. 20) como "estados onde os sistemas se estabilizam 
eventualmente, dependendo das propriedades do sistema”. Apesar dos fatores de estabilidade ou atratores periódicos, o sistema é aberto e outros elementos podem exercer papéis importantes na ASL. Como explicado por LarsenFreeman (1997, p. 146), um sistema complexo não linear exibe "um atrator 'estranho' porque, embora seu ciclo se repita como em um pêndulo, nenhum ciclo se repete da mesma forma ou se sobrepõe a outro ciclo, apesar de sofrer restriçōes dos limites do atrator". Ao mesmo tempo em que ASL está em constante mudança, ela também fica dentro dos limites do que chamamos de aquisição de língua. Não é possível prever como a ASL se desenvolverá, embora possamos dizer que ela é fractal, uma pequena cópia do todo, isto é, uma fração semelhante ao sistema lingüístico como um todo. ${ }^{3}$

Quando examinamos as NALEs, percebemos que não importa o quanto e como os professores planejam, lecionam, avaliam e dão feedback, pois os alunos reagirão de forma diferente e eventos imprevisíveis farão, inevitavelmente, parte de suas experiências de aprendizagem. Diferenças lingüísticas, contextos culturais, razões para aprender e muitos outros componentes do sistema de aquisição afetam e são dinamicamente afetados por outros componentes do sistema. Embora os processos de ASL sejam semelhantes, atratores estranhos ou caóticos irão, constantemente, reconfigurar sua dinamicidade, e os resultados serão diferentes, apesar da semelhança nas condições iniciais. Pequenas perturbaçôes nas condições iniciais e eventos imprevisíveis podem causar resultados importantes, positivos ou negativos. A aparente ordem no sistema de aquisição é na verdade caótica e o caos parece ser fundamental nesse tipo de processo. A ASL depende da interação entre vários elementos do sistema e como o sistema é aberto, ele está sujeito a um contínuo fluxo e influxo de experiências lingüísticas.

A ASL depende da interação entre os vários elementos do sistema e como ele é aberto, está sujeito a um contínuo fluxo e influxo de experiências lingüísticas. Embora ele se auto-organize, o sistema nunca alcança o equilíbrio, mas apenas uma estabilidade temporária.

\subsection{2. À beira do caos}

Velve et al. (2002, p.2) explicam que "as transições de fase ou a beira do caos ocorrem quando o sistema opera no limite da ordem e do caos" e que é nesse ponto que o sistema entra em seu máximo grau de criatividade.

${ }^{3}$ Larsen-Freeman (1997, p.150) nos lembra que a língua é também fractal, pois não é diferente dos outros fenômenos naturais. 
A ordem e o caos coexistem em uma tensão dinâmica. De acordo com Ockerman (1997), o sistema é capaz de coisas notáveis quando está operando na zona entre a ordem e o caos, ou seja, à "beira do caos". Ele explica que a beira do caos é um estado entre a ordem e o caos onde "o maior processamento de informação acontece, onde se correm riscos e novos comportamentos são experimentados" (p. 222). Ele acrescenta que

Há cinco fatores, ou parâmetros de controle, que determinam se um sistema pode se mover para a beira do caos (ou além dele para a desintegração): o ritmo do fluxo da informação, o grau da diversidade, a riqueza da conectividade, o nível da ansiedade contida, e os graus de distribuição de poder. Nos sistemas humanos, esses fatores se combinam em um tipo de tensão criativa onde as pessoas estão ligadas a outras em relações paradoxicais de cooperação/competitividade, inspiração/ ansiedade, e subserviência/ individualidade (...). (OCKERMAN, 1997, p.222)

$\mathrm{Na}$ ASL, podemos considerar alguns fatores que movem o sistema para a beira do caos. São eles: a somatória das experiências com a língua, o grau de diversidade do input, a riqueza das interações, o nível se contenção da ansiedade, e o grau de autonomia ou controle sobre a própria aprendizagem. Tomo por pressuposto que autonomia também implica a idéia de descentralização de poder (Ockerman 1997). Os aprendizes são indivíduos que evidenciam empoderamentos diferenciados com efeito direto em sua autonomia.

Após essa breve revisão do suporte teórico, descrevo na próxima seção o contexto deste estudo sobre narrativas de aprendizagem com o objetivo de entender como se dá a aquisição de uma segunda língua.

\section{0 contexto}

Este estudo tem como corpus trinta e oito NALEs multimídia coletadas em uma disciplina sobre letramento digital, no curso de Letras (Inglês) da UFMG em 2005 e 2006. Os narradores são alunos de Licenciatura em Inglês.

O objetivo da atividade era desenvolver habilidades computacionais, tais como edição de imagens, criação de hiperlinks e ferramentas do processador de texto Word da Microsoft. Para tanto, os alunos deveriam escrever suas narrativas de aprendizagem de inglês incluindo imagens e sons. Para a interação entre os alunos e entre alunos e professora foi utilizada uma lista de discussão hospedada no YahooGroups. Os alunos usavam a lista para enviar suas tarefas, 
resolver dúvidas, e discutir problemas relacionados ao curso. O feedback era dado pelos próprios colegas e pela professora e os alunos poderiam rever seus textos várias vezes antes da versão final. Ao final de duas disciplinas, trinta e sete alunos autorizaram a publicação de seus textos na web [http:// www.veramenezes.com/narmulti.htm]. Para a formação final do corpus, incluí minha própria narrativa. Para este estudo, foi feita também uma entrevista com uma aluna para que eu pudesse entender sua escolha de um de seus hiperlinks. Os resultados serão apresentados na próxima seção.

\section{Análsise dos dados}

Foram feitas várias leituras das NALEs com o objetivo de selecionar excertos que nos ajudariam a compreender o que as experiências dos aprendizes revelam sobre a ASL como um sistema complexo e verificar que tipo de conhecimento sobre ASL emerge desses textos. Algumas imagens foram descartadas para se evitarem problemas com direito autorais. Observei que as aberturas e fechamentos seguiam uma determinada estrutura e que as experiências poderiam ser divididas em 2 grupos principais: dentro e fora da escola. $\mathrm{Na}$ análise, descrevo como os textos se iniciam, como apresentam as experiências e como fecham a narrativa.

\subsection{Aberturas}

A maioria dos narradores inseriram suas próprias fotos coloridas no começo de suas narrativas, como nas figuras 1 e 3 , e um deles escolheu o estilo manga (ver 2).

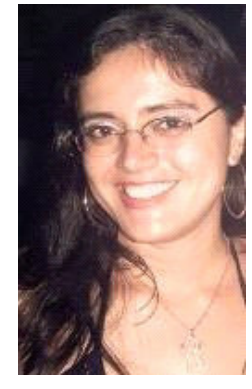

Figura 1: Close

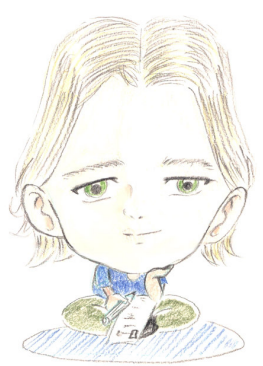

Figura 2: Manga

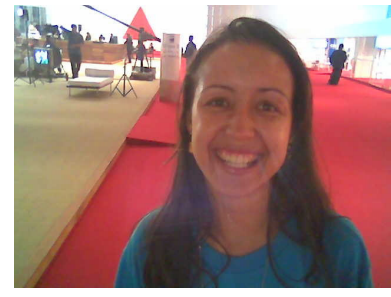

Figura 3: Em um congresso 
As imagens das aberturas estão, geralmente, no formato de close com os narradores olhando para o leitor. Isso é explicado por Kress e van Leeuwen (1996, p.122) como uma configuração visual que "cria uma forma visual de endereçamento direto. É um tipo de reconhecimento explícito do leitor, com o narrador se dirigindo a ele como um "você" visual". A maioria das fotos mostra os aprendizes sorrindo, o que é também explicado por Kress e Leeuwen (1996, p.122) como um tipo de solicitação ao expectador "para entrar em uma relação de afinidade social”. Na figura 3, a narradora optou por exibir sua identidade acadêmica, publicando uma foto tirada no cenário de um congresso. Sua NALE também inclui várias referências a projetos e grupos de pesquisa na universidade e esse conjunto de texto e imagem forma um diálogo coerente com sua vida acadêmica. O texto demonstra também que a ASL é um sistema aberto e que as experiências com a língua não estão restritas à sala de aula.

A forma como os narradores iniciam suas NALEs também varia. Alguns, particularmente os que não incluem suas próprias fotos no começo do texto, se apresentam dizendo seus nomes, falando sobre sua infância, ou descrevendo seus primeiros interesses pela língua, como em (1):

(1)

A long journey...

Well, I dare say my interest in English was born on February 12, 1984 (oh yes, that's my birthday!). I say that because I remember very clearly the time when I

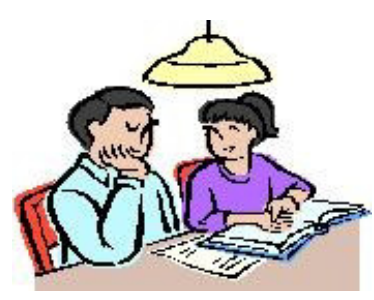
would ask my father how to say such-andsuch words in English. I don't know exactly how old I was then, but I'm sure I was very young. I also remember I had loads of fun turning my father into a walking-talking dictionary. As he himself has always been a language fancier, he would feel pleased to notice my interest in English and would always answer my plausible questions.

One of the first phrases I learned was 'the end'. Can you guess why??? Just because of The Woody Woodpecker cartoon. This phrase would always appear at the end of the cartoon - which, still nowadays, is one of my favorites! 
Ao falar sobre seu pai, a narradora inseriu um hiperlink para a trilha sonora de um filme, "A lenda do Zorro". Quando indagada sobre essa escolha, ela explicou que quando era criança costumava assistir ao filme do Zorro junto com o pai. O sintagma The Woody Woodpecker contém um hiperlink que nos leva à famosa gargalhada do pica-pau. Os dois sons funcionam como índices da significativa presença do cinema e da televisão na experiência de aprendizagem dessa narradora. Outro hiperlink em loads offun conduz o leitor à risada de um bebê e reforça sua afirmação de que seu interesse pelo inglês vem desde a tenra infância. A mesma idéia é vinculada pela imagem do recémnascido. As escolhas das gravuras e sua posição na página podem ser interpretadas como representação do período inicial de sua longa jornada (long journey): de um bebê iletrado a uma criança conduzida pelo pai ao reino do letramento. Esse excerto demonstra que os eventos de aprendizagem são experenciados como hipertextos, reforçando a afirmação de Lemke (2001, p.80) usada na epígrafe "contamos nossas vidas em forma de narrativas, mas as experienciamos como hipertextos". As condiçôes iniciais de sua ASL - o interesse de seu pai pelo inglês e sua motivação precoce - teve um efeito muito positivo em suas experiências posteriores. Seu pai a matriculou em uma escola de idiomas e financiou uma viagem aos Estados Unidos e isso parece ter contribuído para sua decisão de se tornar professora de inglês.

Essa e outras narrativas demonstram que a ASL é um sistema complexo que integra elementos diferentes - família, indústria cultural, artefatos educacionais (livros, dicionários), escola, professores, colegas, etc. - em um processo dinâmico não linear. $\mathrm{Na}$ seção 4.2., apresento alguns excertos que nos ajudarão a compreender a complexidade da ASL.

\subsection{As experiências}

As experiências encontradas em nosso corpus podem ser divididas em 2 grupos: experiências de sala de aula e experiências fora da sala de aula. As experiências de sala de aula exibem atratores periódicos, representados pelo ensino explícito da língua no contexto escolar em oposição às experiências fora da sala de aula, cuja dinamicidade é exibida em atratores estranhos criados pelas experiências culturais e eventos inesperados que colocam o processo de ASL em movimento. Em outras palavras, as experiências de sala de aula são previsíveis e seguem uma estrutura comum enquanto as de fora da sala de aula geram perturbações que podem mudar a rota da aquisição. Várias NALEs apresentam os dois tipos de experiência e entendo que as duas são importantes 
no processo de aquisição. As imagens associadas às diferentes experiências são identificadas como ações sociais, reações transacionais e processos verbais e mentais (KRESS; van LEEUWEN, 1996).

\subsubsection{Dentro da sala de aula}

No primeiro grupo, encontramos narrativas visuais de salas de aula, geralmente tediosas, com os alunos calados, enfileirados em suas carteiras com os professores na frente. Podemos dizer que essas imagens descrevem experiências previsíveis. O tédio é representado tanto nas fotografias quanto nos textos

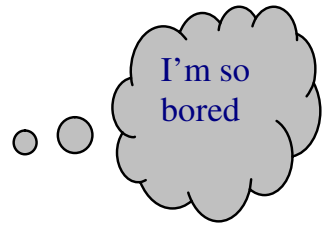

Figura 4: Tédio escritos. Algumas das imagens são acompanhadas de balóes com um vetor apontando para um aluno entediado. Na figura 4, temos a representação de uma reação transacional de um aluno na sala de aula. Como apontam Kress e van Leeuwen (1996, p. 67), esse tipo de reação não é "representado diretamente, mas mediado pelo Reagente, aquele que sente (no caso do balão do pensamento), ou pelo 'Falante' (no caso de um balão com um diálogo)".

As imagens dos professores mostram, de forma geral, ações previsíveis: professores ensinando itens gramaticais ou vocabulário descontextualizado, como se pode ver na figura 3, onde os balóes representam o processo de fala e a vareta na mão da professora funciona como um vetor. Como definem Kress and van Leeuwen (1996, p. 74), "o participante ativo em um processo de ação é aquele do qual emana um vetor". A professora é o ator, a pessoa que fala e faz movimentos. Apesar de não podemos ver os alunos, podemos inferir que eles devem estar sentados em fileiras repetindo as palavras "ceiling" e "floor" ao comando da professora.

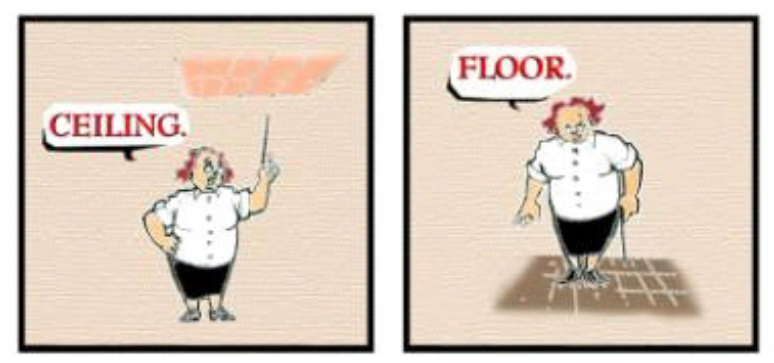

Figura 5: Professora de inglês ${ }^{4}$

${ }^{4}$ Desenho de Rômulo Lagares, bolsista de IC. 
Uma queixa recorrente nas narrativas é o ensino repetitivo do verbo to be como exemplificado pela figura 6. Novamente, temos um processo reacional, onde o narrador avalia sua ASL. Parece que os aprendizes têm consciência de que seus sistemas de ASL precisam de algo diferente para ser colocado em movimento.

Por meio das modalidades verbais e visuais, alguns alunos se representam como membros de uma comunidade de aprendizagem experimentando experiências ruins nas escolas regulares (ex. excerto 2), em oposição às experiências gratificantes vividas fora da sala de aula. Os relatos de experiências boas no ensino básico são raros, no entanto, as aulas de inglês na universidade e nos cursos livres são, freqüentemente,

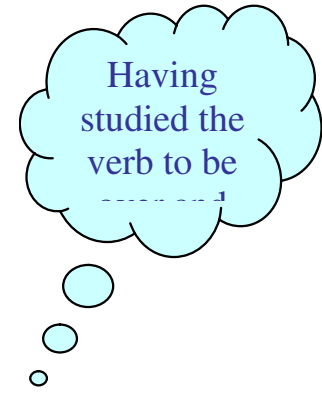

Figura 6: O verbo to be descritas como boas exceções.

(2)

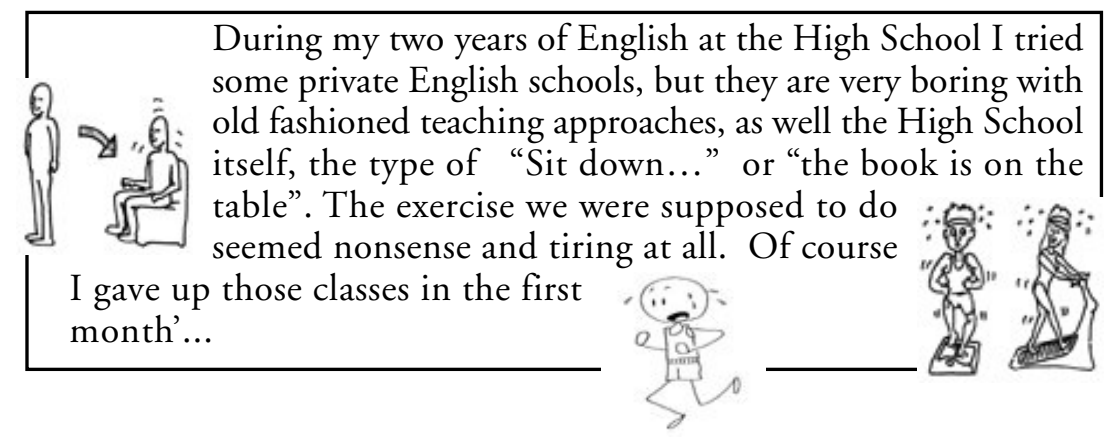

Em (2), o narrador lembra de experiências tediosas vividas em escolas diferentes. Sua afirmação é reforçada por três imagens representando exercícios repetitivos. O primeiro indica o movimento repetitivo de sentar-se, como indica o vetor, ao aprender o comando 'sit down'. A repetição de atividades cansativas é metaforicamente representada pelos dois outros desenhos de pessoas fazendo exercícios físicos repetitivos (andar e correr). As frases 'sit down' e 'the book is on the table' representam clichés do método audio-oral que parece ter sido o adotado na escola desse narrador. Essas frases simbolizam a repetição sem sentido que não é suficiente o bastante para mover o sistema de ASL.

Essa NALE e muitas outras mostram que as experiências de sala de aula, em geral, não levam os aprendizes para a beira do caos, pois elas raramente 
oferecem boas experiências lingüísticas, com diversidade de input e interaçóes produtivas. Ao falar das experiências escolares, os alunos geralmente falam da ansiedade sentida ao serem forçados a executar tarefas aborrecidas que não contribuíam para sua ASL. Uma boa exceção, na universidade, são as aulas de literatura, pois elas lidam com a linguagem como uma prática social, isto é, o inglês é usado para discutir obras literárias. Alguns alunos apontam a importância da literatura em seu processo de ASL dentro e fora da sala de aula. As narrativas também revelam que a maioria dos narradores tem o controle de sua aprendizagem. A próxima seção apresenta algumas dessas experiências autônomas.

\subsubsection{Fora da sala de aula}

O segundo grupo de experiências demonstra que os atratores estranhos ou caóticos são os que fazem a diferença nos processos de ASL. Há evidência suficiente para dizer que os aprendizes são levados à "beira do caos" pelos atratores estranhos que não são encontrados nos contextos tradicionais de aprendizagem e sim fora da sala de aula. Os aprendizes correm risco, exploram a língua e vivem diferentes situações de práticas discursivas. Como já registrado por Nelson (2004, p.102), "a sala de aula não está isolada do mundo. Ao contrário, os aprendizes, e os conhecimentos que eles incorporam, atravessam as fronteiras da sala de aula em redes que se multiplicam e reciclam o conhecimento". As redes de ASL são formadas pelas bandas e canções favoritas como em (3) e (4); literatura como em (3); shows de TV, videogames e jogos de computador; RPGs (Role Playing Games); salas de chat na Internet; interação com outros falantes de inglês, como em (5); e experiências no exterior, como em (6).

O excerto (3) é acompanhado pelas fotos de Radiohead, Led Zeppelin e The Doors. O subtítulo dessa parte da narrativa demonstra como a produção cultural - literatura e música - dá dinamicidade à ASL. As palavras sublinhadas contêm hyperlinks para várias páginas na web e o leitor pode ver fotografias, ouvir canções, ler mais sobre várias bandas e cantores e assistir ao trailer de "The Princess and The Warrior". Uma variedade de opçōes de leitura e de textos orais emerge das rotas imprevisíveis que o leitor pode percorrer para ter uma idéia da experiência do narrador: 
(3)

\section{Literatura e Rock'n'Roll: The Best}

Literature helped me a lot. I learnt and am learning lots of English thanks to Literature. Including, of course, music!!! I always loved music, and by the time I started my course, I was falling in love with Led Zeppelin (see "In The Light" lyrics), Creedence Clearwater

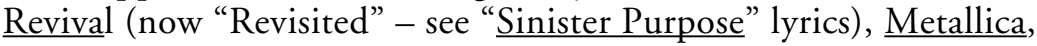

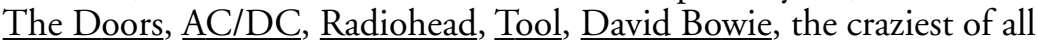
Iggy Pop, Leonard "The Master" Cohen (please listen to "Waiting For The Miracle" - the images are from the film "The Princess and The Warrior"), and others.

A música contribui para o aumento da quantidade de input e não é nenhuma surpresa perceber que quase todos os narradores falam sobre o papel da música em seus processos de ASL. O mesmo narrador do excerto (2) fala sobre o valor da música, referindo-se a um programa de TV brasileiro que usava cançôes pra ensinar inglês no excerto (4). Ele explica que era possível ouvir a musica e cantar acompanhando a letra da música na tela e, também, assistir uma aula com regras de gramática e explicação sobre o vocabulário. O narrador usa uma imagem para representar um processo mental, a metáfora do insight, e tanto a imagem como a afirmação em letras maiúsculas enfatizam que o programa de TV mudou sua crença sobre sua capacidade de aprender inglês. O programa representou uma guinada em sua aprendizagem, a beira do caos, e mudou toda a rota do sistema de ASL.

(4)

And I'll always remember the
music that opened up my eyes to
REALLY COULD UNDERSTAND
despite the classes on the schools
less effective.
It was very fun because watching the program, the English rules
and its words made sense, on the contrary, in the classroom it didn't.
I still remember the phrases of it, like "No crisis arises my life goes
along as it should ... and at the time I found myself singing it and
they are complete sentence that made me think about the language
and its rules, because these rules had a superb explanation from the
program presenter who seems to have an entire domain in the
matter.


O próximo excerto apresenta uma boa experiência de interação com estrangeiros falantes de inglês, o que dificilmente acontece no contexto escolar. O narrador em (5) joga capoeira e isso funciona como um atrator estranho que muda a rota de sua ASL.

(5)

When I was 16 years old I started practicing capoeira, and I also started to have contact with many foreign people. (..) Talking to these people was a great experience for me, because for the first time I was feeling that I could communicate with native speakers, in the target language!!

O excerto (5) é um bom exemplo para comprovar que a ASL é um sistema aberto a experiências inesperadas e que atratores estranhos (ex. capoeira) podem mudar sua rota. Exemplos semelhantes do papel relevante do esporte para a promoção de interações com estrangeiros, afetando positivamente o sistema de ASL, podem ser encontrados em nosso corpus. As viagens parecem constituir outro atrator estranho, pois muitos narradores registram em texto e fotos a importância de se viajar ao exterior. Um exemplo pode ser visto em (6):

(6)

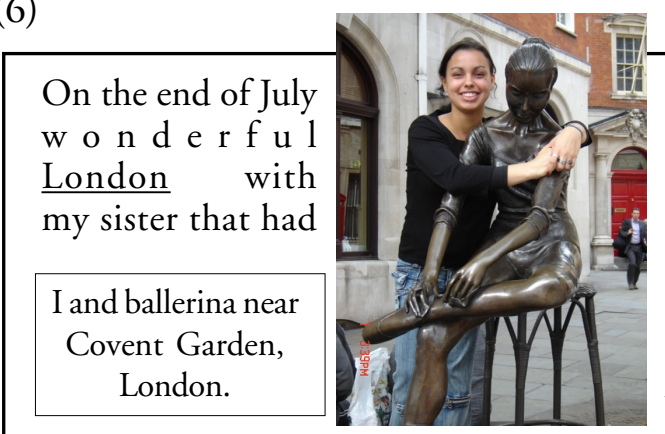

2005 something happened to me. I went to mum and there we met already been living there for some time. Mum stayed only three months, I stayed eight months. Amazing experience. I could finally experience English Language in its natural environment... in a place where I would have to either SPEAK or SPEAK. There was no choice. In the beginning I was so ashamed of my English, it was horrible. Then one day, one guy from New Castle said to me, "You speak very good English," and I thought he just wanted to make me less uncomfortable, but later on I sometimes heard the same comment from other people and slowly I started getting more and more confident. 
Os eventos fora da sala de aula parecem diminuir o nível de ansiedade e mover o sistema de ASL para "a beira do caos" porque eles são responsáveis por uma taxa elevada de práticas sociais de linguagem que fornecem input variado, diversidade de interação e oportunidade para o exercício de autonomia.

Em (6), a narradora, no começo envergonhada, torna-se mais confiante ao obter feedback positivo dos falantes nativos. As fotografias mostram a aprendiz em Convent Garden e seus braços, usando os termos de Kress e van Leeuwen (1996), formam vetores em uma ação não-transacional. Ela tem um objetivo: abraçar a bailarina que está em uma posição não-transacional. A narradora olha para o leitor sorridente, se dirigindo visualmente ao leitor. A imagem funciona como uma metáfora sobre sua "experiência surpreendente" (amazing experience) com a língua inglesa quando sua única escolha era SPEAK or SPEAK (falar ou falar). O abraço simboliza sua total integração com a cultura e com a língua. Ela, também, "abraçou" a língua e sua decisão foi sua "beira do caos", o ponto crítico de sua ASL.

As experiências fora da sala de aula oferecem oportunidades para os aprendizes exercitarem sua autonomia, escolhendo seu próprio percurso em direção à aquisição. Cada NALE é única e os narradores, geralmente, enfatizam essa singularidade em suas considerações finais. Vejamos, na seção 4.3, como os narradores terminam seus textos.

\subsection{Fechamentos}

Os aprendizes, geralmente, fecham seus textos com reflexões sobre a ASL. Como todos eles leram muitas versões das narrativas de seus colegas, eles adquirem consciência de que nenhuma história é igual. Um deles afirmou: "Acho fascinante ver que o processo de aquisição de segunda língua varia tanto de pessoa para pessoa e que não é previsível". Outros fecham seus textos dando conselhos aos leitores como exemplificado pelos seguintes trechos: "Um conselho? Persiga seus sonhos"; "Só você pode escrever a sua história!" e "Uma coisa está bem clara para mim: quando uma pessoa quer, realmente, aprender uma outra língua, ela encontrará o caminho para fazer isso acontecer, não importa quão difícil isso possa ser ou quão pequenas sejam as ajudas que ela consiga."

A maioria dos narradores está consciente de que estão envolvidos em um sistema complexo sempre em movimento ao fazerem afirmaçôes tais como "O processo de aprendizagem nunca termina"; "Eu nãn acho que acabou ou que acabará um dia”; ou, ainda, "To be continued... U (A ser continuada...). 
Eles entendem que o sistema é aberto, como registrado na fala final de um dos aprendizes: "cada dia é um novo dia com novas coisas para aprender". Percebem também que o sistema é não-linear como descrito por outro aprendiz que diz "Eu sei que a forma como estudei inglês não foi 'normal', ou seqüencial como é feito nos cursos particulares de inglês, mas meu inglês foi construído de forma 'artesanal' com experiências e sotaques diferentes."

\section{Conclusão}

As NALEs demonstram que as experiências de aprendizagem oscilam entre dois pontos - atividades de sala de aula que são descritas como previsíveis e repetitivas e uma fase mais criativa onde a agência permeia as experiências, mas elas são interconectadas e influenciam e são influenciadas reciprocamente. A primeira é responsável pela metalinguagem e o conceito de língua que prevalece é o de um conjunto de léxico e de estruturas gramaticais. A segunda está relacionada a práticas sociais da linguagem quando os aprendizes usam a língua para fazer coisas: ouvir música, ver filmes, ler diferentes tipos de textos e interagir com falantes do inglês. A língua é então entendida como comunicação. Convergência e divergência das diferentes experiências compóem o processo de ASL e um alto grau de complexidade emerge, fazendo com que cada estágio de aprendizagem seja diferente dos anteriores. Mudanças e perturbaçóes acontecem durante esse processo e elas dão dinamicidade ao processo. As NALEs demonstram como o processo se auto-organiza e move em direção ao sucesso. Existem estabilidades temporárias, mas o sistema nunca alcança o equilíbrio.

O uso de imagens, textos, sons e hipertextos são essenciais para representar as identidades individuais, ansiedade, felicidade, desconforto e tensões vivenciadas pelos aprendizes durante seu processo de ASL. Alguns textos multimídia usam muito material visual e outros são mais econômicos, como já demonstrei em Paiva (2006, p.37),

Palavras, imagens e sons juntos formam um todo que é maior que a soma de suas partes. Os textos multimídia ativam a criatividade e a imaginação dos narradores e têm impacto significativo em nossa comunidade de aprendizagem, pois os participantes não apenas produzem e compartilham um novo tipo de texto, mas refletem sobre seus processos passados e presentes de aprendizagem ao mesmo tempo em que auxiliam seus pares a desenvolver e melhorar habilidades lingüísticas e computacionais. 
As NALEs mostram que a ASL é um sistema complexo e que a segunda língua não é produto de contextos formais de aprendizagem. Ela emerge da interação entre diferentes redes sociais (família, produção cultural, escola, outros falantes) e fatores cognitivos e afetivos.

\begin{abstract}
This paper reflects upon the acquisition of English language, understood as a complex system, in the light of an emic approach. In order to do that, it discusses aspects of narrative research, of multimodality, and of the complexity of second language acquisition. As empirical evidences of acquisition, the article presents excerpts of multimedia language learning narratives through wich the authors reveal aspects of their learning processes by means of texts, hypertexts, images and sounds. Those narratives show that the acquisition process is a complex system and that the second language emerges from the interaction among the different learning experiences lived inside and outside the classroom. KEY-WORDS: acquisition, narrative research, multimedia, complexity.
\end{abstract}

\title{
Referências
}

BENSON, P.; NUNAN, D.C. (Ed.). Special issue on the experience of language learning. Hong Kong Journal of Applied Linguistics, v. 7, n.2, 2002.

BENSON, P.; NUNAN, D. (Ed.). Learners' stories: difference and diversity in language learning. Cambridge: Cambridge University Press, 2005.

ELLIS, N. C. At the interface: dynamic interactions of explicit and implicit language knowledge. Studies in Second Language Acquisition, v. 27, n.2, p. 305-352, 2005.

GILSTRAP, D. L. Strange attractors and human interaction: leading complex organizations through the use of metaphors. Complicity, v.2, n.1, p. 55-69, 2005. Disponível em <http://www.complexityandeducation.ualberta.ca/ COMPLICITY2/Complicity2.htm>. Acesso em: $26 \mathrm{dez} .2006$.

KRESS, G.; van LEEUWEN, T. Reading images: the grammar of visual design. London: Routledge, 1996.

LARSEN-FREEMAN, D. Chaos/complexity science and second language acquisition. Applied Linguistics, v. 18, p. 141-165, 1997.

LARSEN-FREEMAN, D. Second language acquisition and Applied Linguistics. Annual Review of Applied Linguistics, n. 20, p. 165-168, 2000.

LEWIN, R. Complexity: life at the edge of chaos. New York: Macmillan, 1992. LAKOFF, G.; JOHNSON, M. Metaphors we live by. Chicago and London: The University of Chicago Press, 1980. 
LEMKE, J. Discursive technologies and the social organization of meaning. Folia Linguistica, v. 35, n.1-2, p. 79-96, 2001.

McGROARTY, M. Constructive and constructivist challenges for Applied Linguistics. Language Learning, v. 48, n. 4, p. 591-622, 1998.

MURPHEY, Tim; CHEN, Jin; CHEN, Li-Chi. Learners' constructions of identities and imagined communities. In: BENSON, P.; NUNAN, D. (Ed.). Learners' stories: difference and diversity in language learning. Cambridge: Cambridge University Press, 2005. p. 83-100.

MURPHEY, T. (Ed.) Language learning histories II. Nagoya, Japão: South Mountain Press, 1998.

MURPHEY, T. (Ed) Language learning histories. Nagoya, Japão: South Mountain Press, 1997.

NELSON, C. P. The role of networks in learning to write. Proceedings of the 2004 Complexity Science and Educational Research Conference (p. 91-105). September 30 - October 3, Chaffey's Locks, Ontario, Canada, 2005. Disponível em: <http://www.complexityandeducation.ualberta.ca/conferences/2004/ proceedings.htm>. Acesso em: 19 jan. 2007.

OCKERMAN, C. Facilitating and learning at the edge of chaos: expanding the context of experiential education. AEE International Conference Proceedings, 1997. Disponível em: <http://eric.ed.gov/ERICDocs/data/ericdocs2/ content_storage_01/0000000b/80/23/71/61.pdf >. Acesso em: 19 dez. 2006. PAIVA, V. L. M. O. Memórias de aprendizagem de professores de língua inglesa. Contexturas, v. 9, p 63-78, 2006 a.

PAIVA, V. L. M. O. Autonomia e complexidade. Linguagem e Ensino, v. 9, n. 1, p. 77-127. 2006b.

PAIVA, V. L. M. O. Online teacher training and multimedia narratives. Essential Teacher, v. 3, n. 4, p. 34-37, 2006c.

PAIVA, V. L. M. O. Autonomia e complexidade: uma análise de narrativas de aprendizagem. In: FREIRE, M. M; ABRAHÃO, M. H. V; BARCELOS, A.M.F (Org.). Lingüistica aplicada e contemporaneidade. Campinas, São Paulo: Pontes, ALAB, 2005. p.135-153

PAVLENKO, A. Language learning memoirs as gendered lives. Applied Linguistics, v. 22, n. 2, p. 213-240. 2001.

SHOAIB, A.; DÖRNYEI, Z. Affect in lifelong learning: exploring L2 motivation as a dynamic process. In: BENSON, P.; NUNAN, D. (Ed.). Learners'stories: difference and diversity in language learning. Cambridge: Cambridge University Press. 2004. p. 22- 41. 
SO, S.; DOMINGUEZ, R. Emotion processes in second language acquisition. In: BENSON, P.; NUNAN, D. (Ed.). Learners'stories: difference and diversity in language learning. Cambridge: Cambridge University Press. 2004. p.83-100.

SWAIN, M.; MICCOLI, L. S. Learning in a content-based, collaborativelystructured course: the experience of an adult ESL learner. TESL Canada Journal, v. 12, n.1, p.15-8, 1994.

VELVE, B.; GREER, A.; DEIRDRE, L.; ESCOTT-STUM, S. Chaos theory as a planning tool for community-based educational experiences for health students. Journal of Allied Health, v. 31, n. 3, p.147-152. 2002. Disponível em: <http://www.findarticles.com/p/articles/mi_qa4040/is_200210/ai_n9123126>. Acesso em: dez. 2006.

Recebido em 10 de setembro de 2008. Aceito em 30 de setembro de 2008. 